DOE/ER/12101-2

\title{
PHOTOASSISTED OXIDATION OF
} OIL FILMS ON WATER

\author{
Progress Report \\ January 1991 - December 1991 \\ Adam Heller and James R. Brock \\ Department of Chemical Engineering \\ The University of Texas at Austin \\ Austin, Texas 78712-1062
}

AUGUST 1991

PREPARED FOR THE U.S. DEPARTMENT OF ENERGY

UNDER GRANT NUMBER DE-FG05-90ER12101 


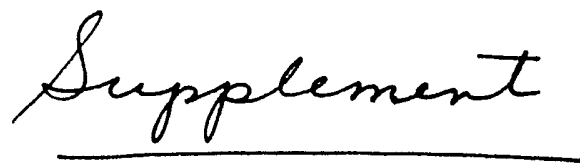

Model System for Lifetime and Quantum Efficiency Measurement of Beadattached Floating Photocatalysts

The quantum efficiency for the floating photocatalyst-coated glass microbeads of $5 \%$ mentioned in the progress report of August 13, 1991, has now been revised to $9 \%$ by hydrogen reduction of the microbeads. Our efficiency objective remains $35 \%$, the efficiency observed in $\mathrm{TiO}_{2}$ slurries.

$$
(9-13-91)
$$

\section{DISCLAIMER}

This report was prepared as an account of work sponsored by an agency of the United States Government. Neither the United States Government nor any agency thereof, nor any of their employees, makes any warranty, express or implied, or assumes any legal liability or responsibility for the accuracy, completeness, or usefulness of any information, apparatus, product, or process disclosed, or represents that its use would not infringe privately owned rights. Reference herein to any specific commercial product, process, or service by trade name, trademark, manufacturer, or otherwise does not necessarily constitute or imply its endorsement, recommendation, or favoring by the United States Government or any agency thereof. The views and opinions of authors expressed herein do not necessarily state or reflect those of the United States Government or any agency thereof. 


\section{PROJECT OUTLINE AND OBJECTIVES:}

The objective of the project is to develop $\mathrm{TiO}_{2}$-based photocatalysts for the solar assisted oxidative dissolution of oil slicks. In a $\mathrm{TiO}_{2}$ crystal, absorption of a photon generates an electron-hole pair. The electron reacts with surface-adsorbed oxygen, reducing it to hydrogen peroxide; the hole directly oxidizes adsorbed organic compounds, usually via an intermediate $\mathrm{OH}$ radical. Since the density of $\mathrm{TiO}_{2}(3.8 \mathrm{~g} / \mathrm{cc}$ for anatase, $4.3 \mathrm{~g} / \mathrm{cc}$ for rutile) is greaterthan that of either oil or seawater, $\mathrm{TiO}_{2}$ crystals are attached to inexpensive, engineered hollow glass microspheres to ensure flotation on the oil slick surface. Portions of the microsphere surface not covered by $\mathrm{TiO}_{2}$ are made olcophilic so that the microbeads will be preferentially attracted to the oil-air interface.

Based on our latest estimate, one ton of our engineered photoactive microbeads with will be capable of solubilizing more that 35 tons of oil per week. Products of the photocatalytic oxidation are more soluble in water and biological oxidation of crude oils is accelerated when the oil is made more water soluble. Thus, photocatalytic oxidative solubilization is complementary to bioremediation.

In this second year, progress has been made in understanding the solar collection process by the photoactive microbeads, in optimization of the application of the photocatalyst to the microbeads, in development of photocatalyst with maximum quantum efficiency, and in process development for the engineered microbeads.

\section{PROGRESS:}

\section{SOLAR UV FLUX COLLECTION BY CLASS MICROBEADS}

In order to determine the fraction of the solar UV flux captured by the $80 \mu \mathrm{m} \quad \mathrm{TiO}_{2}$ coated hollow glass microbeads floating at the oil/air interface, the optics of the system has been analyzed. Some of the results are summarized in this section.

The collection optics depends on the complex refractive indices of the glass, of the $\mathrm{TiO}_{2}$, and the oil for the UV band of interest--that is, $350-360 \mathrm{~nm}$. Depending on their composition, the aluminosilicate glasses studied had real indices ranging from 1.48 to 1.73 at $350 \mathrm{~nm}$. In general, the literature indicates that many crude oils absorb strongly in the UV. This was confirmed by experimental measurement of the absorbances of three crude oils (Arab light, Arab heavy, Basrah light), measured at $350 \mathrm{~nm}$. These absorbances were large, ranging from $1.5-3.0 \times 10^{4} \mathrm{~cm}^{-1}$. For example a $2 \mu \mathrm{m}$ thick layer of one of these crudes will absorb $95 \%$ of the solar UV flux at $350-360 \mathrm{~nm}$. This indicates that it is essential that the hollow glass beads have sufficiently low density that they float on the surface at the oil/air interface.

The angular dependence of collection efficiency of sunlight by the $\mathrm{TIO}_{2}$ coated glass microbeads floating on oil slicks and lightguiding the solar UV flux to the $\mathrm{TiO}_{2}$ crystallites attached to the surface of the glass microbeads has been modelled and analyzed using a Monte Carlo analysis. In this analysis the aluminosilicate microbeads were $80 \mu \mathrm{m}$ in diameter with refractive indices ranging from 1.48 to 1.90; the oil was assigned an index of 1.56 . Collection efficiencies were determined as a function of the fraction of the bead area covered by optically thick $\mathrm{TiO}_{2}$ crystallites, as shown in Fig. 1. Also, Fig.. 2 presents the collection efficiencies calculated for various microbead refractive indices with surface coverage as parameter. Fig. 3 shows the collection efficiency as a function of wall thickness of $80 \mu \mathrm{m}$ diameter hollow glass microbeads with fractional surface coverage by $\mathrm{TiO}_{2}$ as a parameter; it is evident from this figure that wall thickness plays a minor role in determining collection efficiency. These calculations serve as a guide in selecting optimum surface coverage and glass refractive indices in engineering the microbeads.

Principal conclusions from these efficiency calculations are as follows: 
(1) As long as the index of refraction of the glass exceeds that of the oil, about half of the incident solar photons are collected at $35 \%$ coverage of the bead surface by attached $>0.2 \mu \mathrm{m}$ diameter $\mathrm{TiO}_{2}$ particles.

(2) The collection efficiency peaks near $70 \%$ coverage where about $65 \%$ of the photons are collected. The remaining photons are reflected.

(3) The collection efficiency increases with the index of refraction of the glass.

(4) At $40 \%$ bead surface coverage by $\mathrm{TiO}_{2}$ particles, the majority of the photons exciting the $\mathrm{TiO}_{2}$ particles reach these from their backside, i.e. the photons are collected in and are propagated by the glass-wall of the bead to the $\mathrm{TiO}_{2}$ particles, not absorbed by particles facing the sun. Thus oil-immersed $\mathrm{TiO}_{2}$ particles at the "bottom" of the bead are effective catalysts. A single monograin layer of 100-200nm particles is, however, essential. Multiple particle layers must be avoided because holes generated in the layer on the glass recombine on their way to the oil interface at boundaries paralleling the bead surface.

(5) Because the crude oils strongly absorb the relevant ultraviolet photons, the hollow beads must be light enough to be less than half immersed in the oil.

(6) Because there is only a small incremental gain in photon collection efficiency where the beads are more than $40 \%$ covered with $\mathrm{TiO}_{2}$, the residual $60 \%$ bead surface can be covered with an oleophilic monolayer so as to keep the beads at the oil/air interface, rather than at the oil/water interface.

In summary, the optical microbeads need to be engineered as follows:

Diameter:

$50-150 \mu m$

Material: Water insoluble aluminosilicate or aluminoborosilicate glass of high index of refraction at $360 \mathrm{~nm}$.

Wall Thickness: $\quad 5 \mu \mathrm{m}$ or less to assure low bead density, i.e. that at least half of the bead is above the oil.

Photocatalyst coverage: Under optimum conditions, $\mathrm{TiO}_{2}$ particles should cover $35 \pm 5 \%$ of the bead surface, with the residual $65 \%$ covered by the oleophilic film. The oleophilic film on the $\mathrm{TiO}_{2}$ particles is rapidly photooxidized, while the oleophilic film on the glass itself is photostable.

\section{Catalysis of the Rate of Electron Transfer from Photocatalyst Particles to Dissolved Oxygen.}

Mathematical modeling confirmed by experiments showed that $\mathrm{O}_{2}$ mass transfer to $\mathrm{TiO}_{2}$ particle surfaces does not limit the quantum efficiency in $\mathrm{TiO}_{2}$ particle slurries, even at high crncentrations of the oxidizable organic component. The analysis and the measurements also showed that in such slurries, where photogenerated holes oxidize the organic constituents, the quantum efficiency is limited by the rate of transfer of the excess electrons left on the particles (after hole transfer) to dissolved oxygen. In the absence of excess electrons, the photogenerated holes react rapidly and efficiently with water adsorbed on the photocatalyst (to produce oxidizing $\mathrm{OH}$ radicals and protons) or directly with the adsorbed organic material. Unless there is an equally rapid process whereby the excess co-generated electrons are transferred to molecular oxygen, the particles become charged with electrons. When the surface and near surface density of electrons increases, the quantum efficiency declines ultimately to nil. In contrast with the rapid hole photooxidation reactions that involve single electron or hole transfer, the $\mathrm{O}_{2}$ reduction process to the first stable intermediate 
peroxide involves simultaneous transfer of two electrons and is intrinsically slow on $\mathrm{TiO}_{2}$ surfaces. This slow transfer leads to electron accumulation and to poor quantum efficiencies in the photocatalytic process. We found, however, that co-catalysts, particularly palladium in trace amounts $\left(0.01 \%\right.$ of the $\mathrm{TiO}_{2}$ or $0.001 \%$ of the bead) accelerate the $\mathrm{O}_{2}$ reduction. The cocatalysts can be applied selectively to the surface of the $\mathrm{TiO}_{2}$ particles in a cost-effective manner by photoelectrodeposition.

Figure 4 shows the results of a slurry experiment for measuring the electron accumulation on the $\mathrm{TiO}_{2}$ particles in the absence of a co-catalyst, and Fig. 5 shows the same in the presence of $\mathrm{Pd}$ as co-catalyst.

Palladium effectively co-catalyzes the two-electron reduction of $\mathrm{O}_{2}$ on $\mathrm{TiO}_{2}$ particles in the presence of an excess of a photooxidizable compound also in $0.3 \mathrm{M}$ aqueous $\mathrm{NaCl}$. The amounts of the $\mathrm{Pd}$ required are small enough so as not to affect the process economics. Although $\mathrm{Pd}$ can be oxidatively dissolved as $\mathrm{PdCl}_{4}$ dissolution is not a problem in the presence of an excess of organics, those preferentially oxidized.

\section{Attachment of Photocatalyst Particles to Beads:}

Two methods for attachment of $\mathrm{TiO}_{2}$ particles to beads have been developed; one based on coupling with a silane, the second based on physisorption followed by thermal bonding. Because of the simplicity of the latter method, it is preferred. Because only a few of the commercial titania types physisorb and because these have a smaller than desired crystallite size $(30-50 \mathrm{~nm})$ and form multilayer coatings on the glass beads, the quantum efficiency of the beads is only of $\sim 2 \%$. The problem is that in multigrain-thick particle layers piled on each other carrier recombination at grain boundaries paralleling the bead surface lowers the quantum efficiency. A second problem is that the beads formed by the process are completely covered with $\mathrm{TiO}_{2}$ particles. As a result, if coated with an oleophilic film (e.g. by reacting the beads with Glassclad $6 C^{\circledR}$, a chlorine-terminated poly dimethyl siloxane from HWS America, Inc., Piscataway, NJ) the oleophilic films turn hydrophilic upon photooxidation, causing the beads to migrate to the water interface upon UV exposure equivalent to one-half day on the ocean surface. Thus the greatest current challenge is to produce microbeads that are only partially $(30-40 \%)$ covered with large $(>100 \mathrm{~nm})$ crystallites. To do so a facility for controlled bead production is now being built. The process is implemented as a modified version of the commercial sol-gel process for the manufacture of hollow glass microbeads from silicon, aluminum and boron alkoxides, resulting in aluminoborosilicate beads. In the process $\mathrm{TiO}_{2}$ crystallites of the required diameter $(100-200 \mathrm{~nm})$ will be bound securely to the high surface area, porous, dry gel prior to heating to glass-forming at high temperature. The process is engineered for forming thin-walled beads that are about $1 / 3$ coated with 100$200 \mathrm{~nm}$ monocrystals of the photocatalyst. The process is designed to match manufacturing capabilities of microbead suppliers such as PQ Corporation in Conshohocken, $\mathrm{Pa}$. The flowchart for the process is shown in Figure 6.

Model System for Lifetime and Quantum Efficiency Measurement of Bead-attached Floating Photocatalysts.

The model system chosen for convenience of analysis is the photoassisted oxidation of 3octanol to 3-octanone on the surface of $0.3 \mathrm{M}$ aqueous $\mathrm{NaCl}$. This reaction, like most other photoassisted oxidation processes, is "current doubling", i.e. the first electron from the organic compound is moved in an activated process, while the second moves spontaneously. Thus, at unit quantum efficiency, the two electrons involved in oxidation of the alcohol to the ketone require only a single photon. In experiments in homogeneously distributed aqueous $\mathrm{TiO}_{2}$ slurries, each photon produced 0.35 ketone molecules, the quantum efficiency being $70 \%$ if current doubling is not considered and $35 \%$ if it is.

In coated glass microbeads, the initial quantum efficiencies have bcen only $5 \%$, because the $\mathrm{TiO}_{2}$ excitation has been dominantly by photons propagating in the glass walls (reaching the backside of the multigrain thick $\mathrm{TiO}_{2}$ films) and because the carriers recombined in the 
multilayer's grain boundaries that ran parallel to the bead-surface.

Recently we were able to grow the $\mathrm{TiO}_{2} 30-50 \mathrm{~nm}$ crystallites by heating to $800-1000^{\circ} \mathrm{C}$ in vacuum for $72 \mathrm{~h}$ to monograins of the desired $100-200 \mathrm{~nm}$ dimension (Figs. $7 \mathrm{a}$ and $7 \mathrm{~b}$ ). Our objective is to achieve quantum efficiencies similar to those observed in the particle slurries (35\%).

\section{Undate on Process Economics and Integration with Microbial Biodegradation}

The cost of the proposed photoassisted oxidation process can be reduced through integration with the emerging biodegradative process for photodissolution of oil slicks through microbial digestion. These processes are limited in their rate by the extremely low solubility of the oil in water. If, however, the oil is slightly solubilized in seawater through partial oxidation of the hydrocarbons, the biodegradation process is quite rapid. Thus, biodegradation and a photoassisted oxidation are complementary. The rate of the combined processes will be higher, and the total cost reduced.

The cost of the photoassisted oxidation catalyst is now estimated as follows: the prices of $\$ 600$ $\$ 1,200$ per ton for microbeads (constituting $\sim 85 \%$ of the active product), of $\$ 1,600$ per ton for $\mathrm{TiO}_{2}$ photocatalyst (constituting about $15 \%$ of the active product) have been cunfirmed. The cost of $\mathrm{Pd}$ co-catalyst per ton, $(0.001 \%$ of the beads) is estimated at $\$ 100$ per ton of beads. Processing is estimated at $\$ 1,500 /$ ton. Shipping, loading and unloading (application) costs, obtained from the ore-shipping and pumping industry, are less than $\$ 300 /$ ton. Thus the approximate total bead cost is $\$ 3,000 /$ ton. At $50 \%$ quantum efficiency, 1 ton of $\sim 100 \mu \mathrm{m}$ diameter beads will photosolubilize 5 tons of oil per day, when the oil is photosolubilized for bacterial biodegradation by oxidizing one carbon in six. Thus the projected cost is a few percent of the cleanup costs of recent major oil spills.

\section{Future Plans}

Mathematical analysis will be done to find the optimum parameters of the bead. It will involve the Monte Carlo technique along with the methods of geometrical optics. The optimum parameters of the glass beads such as diameter, index of refraction, and the inner radius will be examined to increase the effectiveness of the photooxidation of the oil slicks in the field of the scattered sunlight Also, the area of the bead's surface covered by titanium dioxide that maximizes UV light absorption by the $\mathrm{TiO}_{2}$ coating in natural conditions, should be evaluated. Estimation of the economics of the final technology should be done. Based on these optimum conditions, a final estimation of the economics of the method will be possible.

A unit for producing hollow glass microbeads, $30-40 \%$ coated with $100-200 \mathrm{~nm} \mathrm{TiO}_{2}$ crystallites and $60-70 \%$ coated with a glass-bound poly(dimethyl siloxane) making the beads oleophilic is under construction. The unit will allow control of (a) the glass composition and thereby the refractive index, softening point and resistance to corrosion in seawater; (b) bead diameter; (c) density and wall thickness; (d) attachment of and surface coverage by $\mathrm{TiO}_{2}$ particles; (e) coverage of the residual glass with covalently-bound oleophilic films. Simultaneously the process for growing oi $\mathrm{TiO}_{2}$ monograins of $100-200 \mathrm{~nm}$ diameter from smaller crystallite multilayers will be developed so as to avoid recombination at grain boundaries parallel to the bead surface.

The $\mathrm{TiO}_{2}$ on the beads will be co-catalyst activated by photoelectrodeposition of trace amounts of $\mathrm{Pd}$ on their surface. The variation of the quantum efficiency with co-catalyst coverage of the bead attached $\mathrm{TiO}_{2}$ particles will be determined. The engineering objective will be an operational life of 2 weeks for the photocatalytic microbeads, resulting in the dissolution of 35 tons of slick per week per ton of beads. Photosolubilization experiments, combined with bacterial biodegradation of the photosolubilized model oils, and subsequently crudes, will nex: be carried out. 


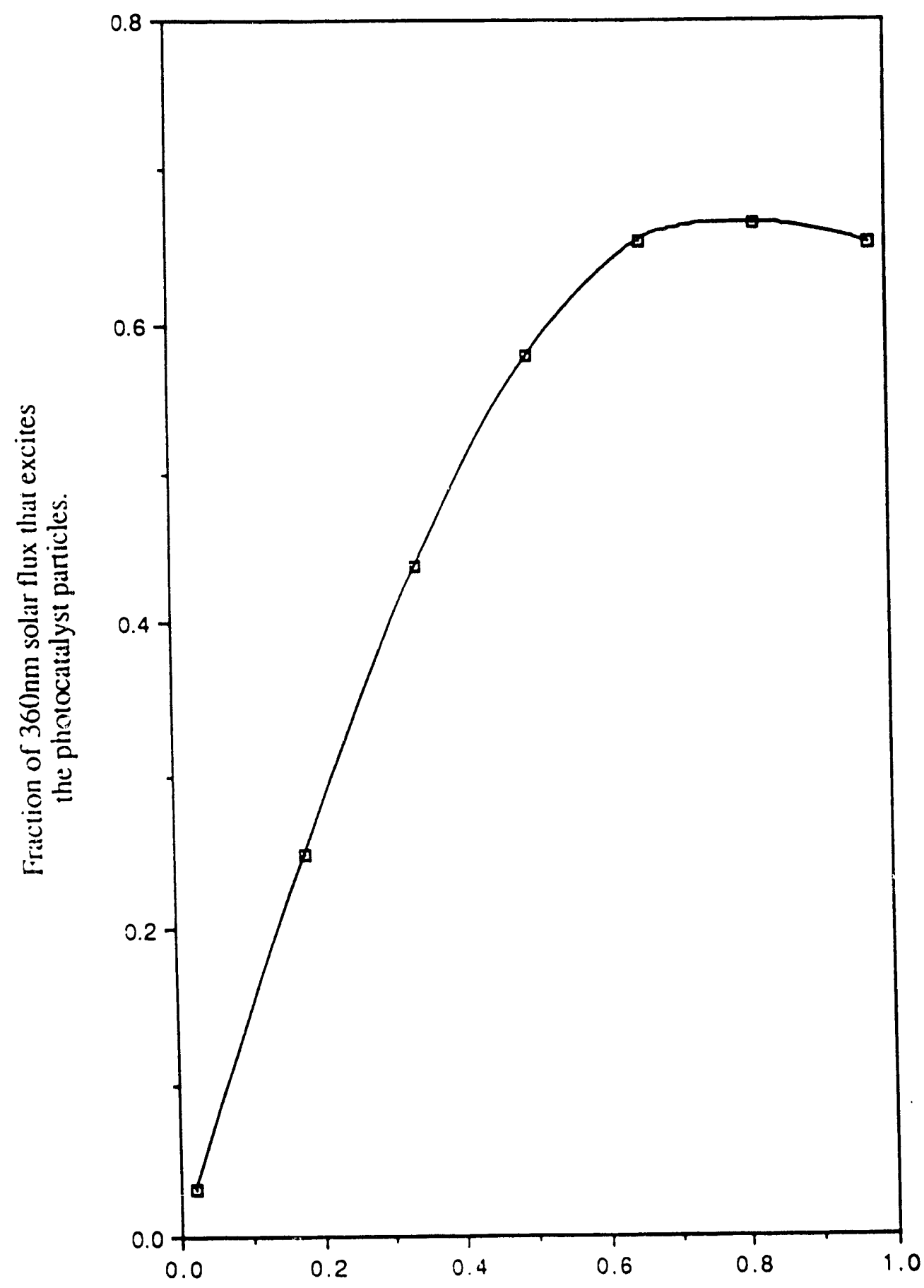

Fraction of microbead surface coated.

Fig. 1: Calculated fraction of the incident solar photons propagated to and absorbed by $\mathrm{TiO}_{2}$ particles attached to hollow glass microbeads floating on oil films as a function of coverage of the bead by the $\mathrm{TiO}_{2}$ particles. The curve shown is for $80 \mu \mathrm{m}$ diameter beads having $10 \mu \mathrm{m}$ aluminosilicate walls of $n=1.53$ floating on an oil slick of $n=1.56$. The $\mathrm{TiO}_{2}$ particles are assumed to be optically thick. 


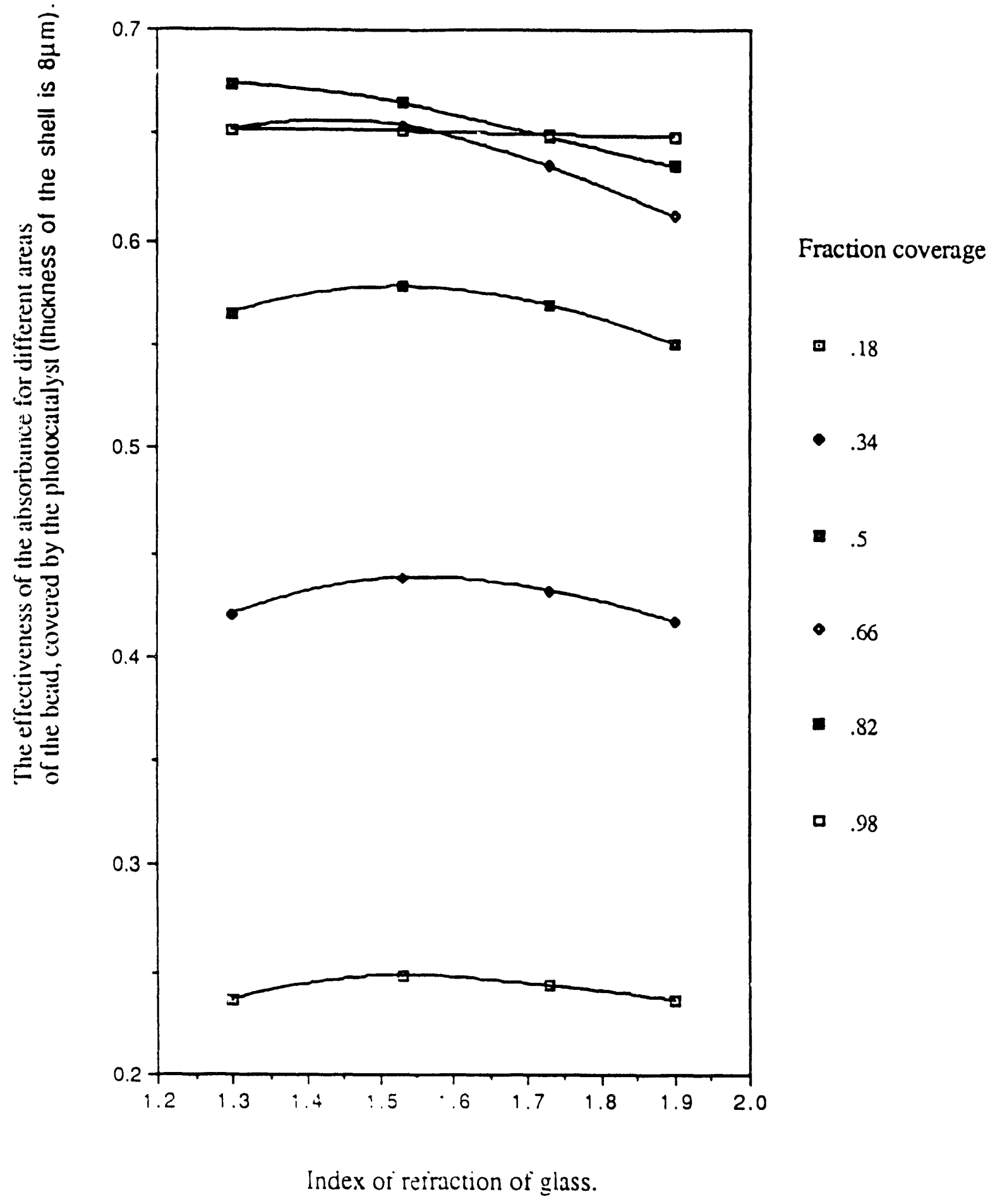

Fig. 2. Calculated fraction of the incident solar photons propagated to and absorbed by hollow glass microbead-attached $\mathrm{TiO}_{2}$ particles on oil films of noil=1.56 as a iunction of the index of refraction of the glass of the beads. Bead ciameter $80 \mu \mathrm{m}$, wall thickness $8 \mu \mathrm{m}$. 


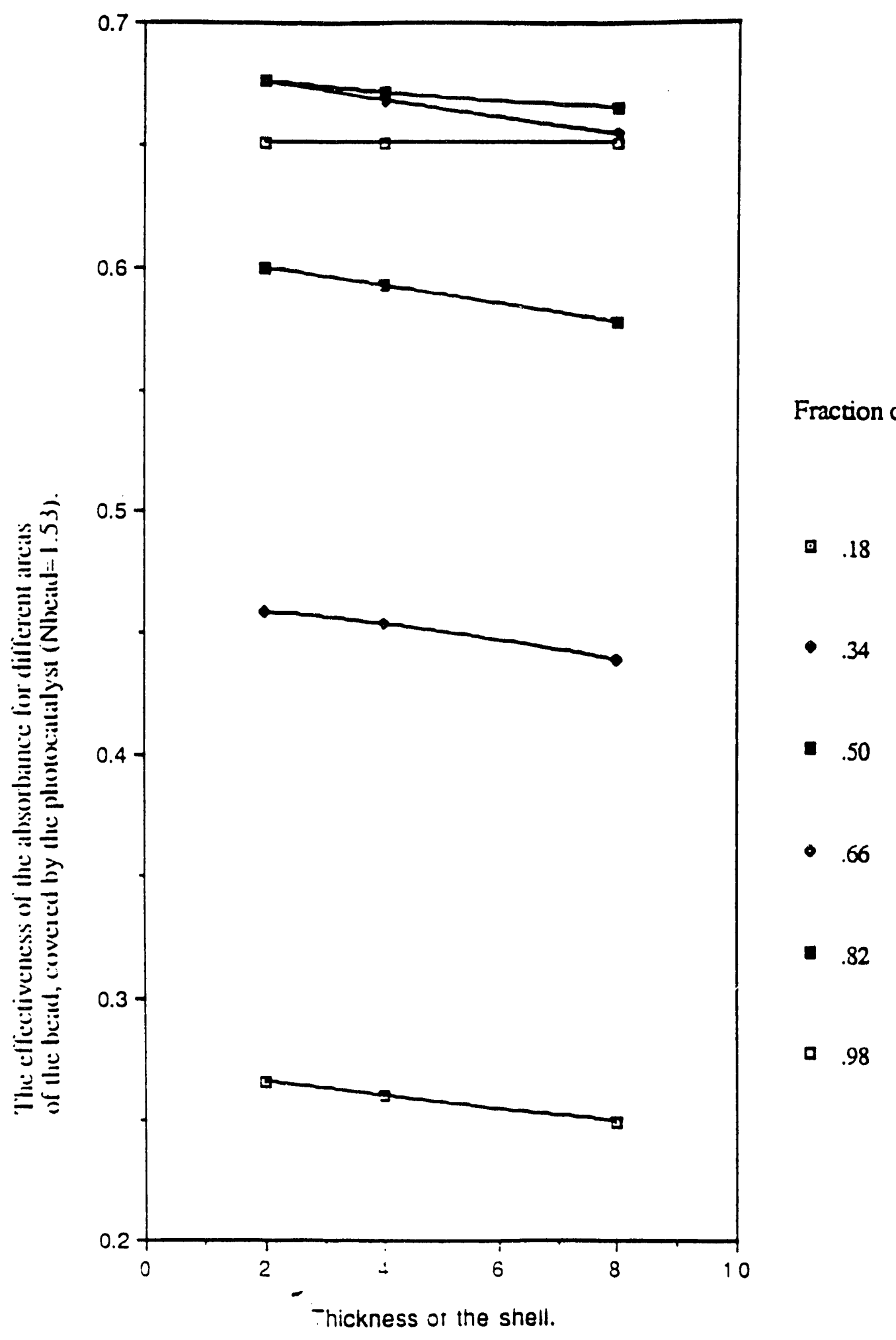

Fig. 3. Calculated fraction of the incident solar photons propagated to and absorbed by hollow glass microbead-attached $\mathrm{TiO}_{2}$ particles on $n_{\text {oil }}=1.56$ oil films for $80 \mu \mathrm{m}$ diameter beads of $n_{\text {glass }}=1.53$, as a function of the thickness of the glass wall of the hollow beads. 


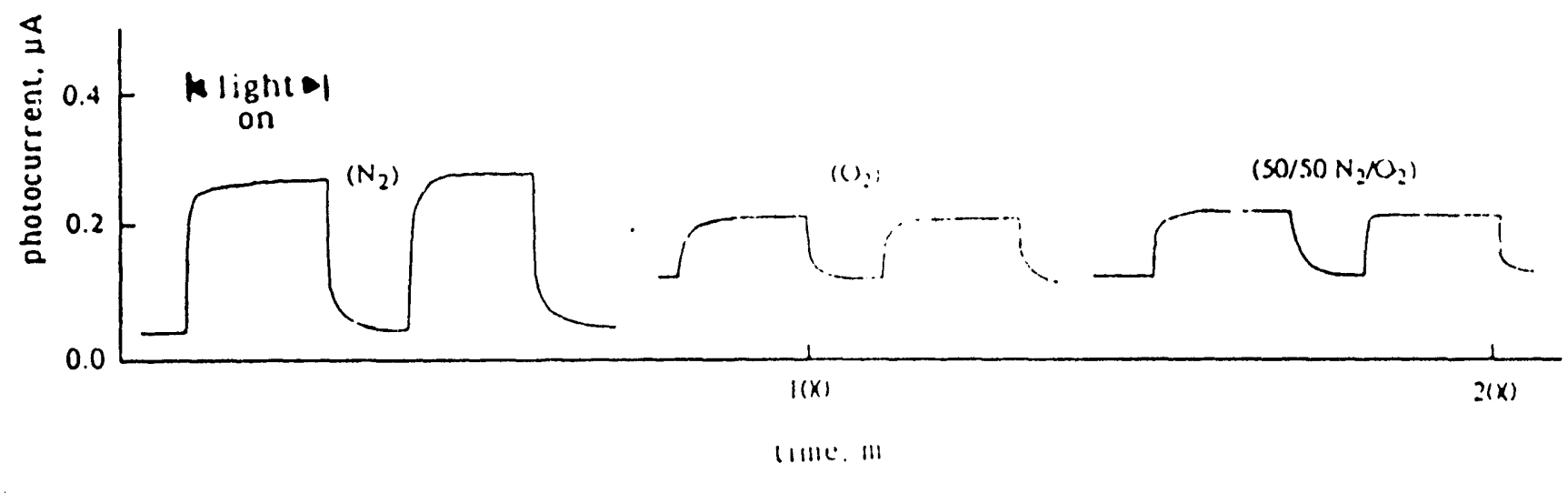

Fig. 4: Dependence of the electron collection current from slurried $\mathrm{TiO}_{2}$ particles by a vitreous carbon electrode maintained at $350 \mathrm{mV}$ vs $\mathrm{Ag} / \mathrm{AgCl}$ on the partial pressure of $\mathrm{O}_{2} .0 .3 \mathrm{M} \mathrm{NaCl}, 1.6 \mathrm{M}$ methanol in water. 


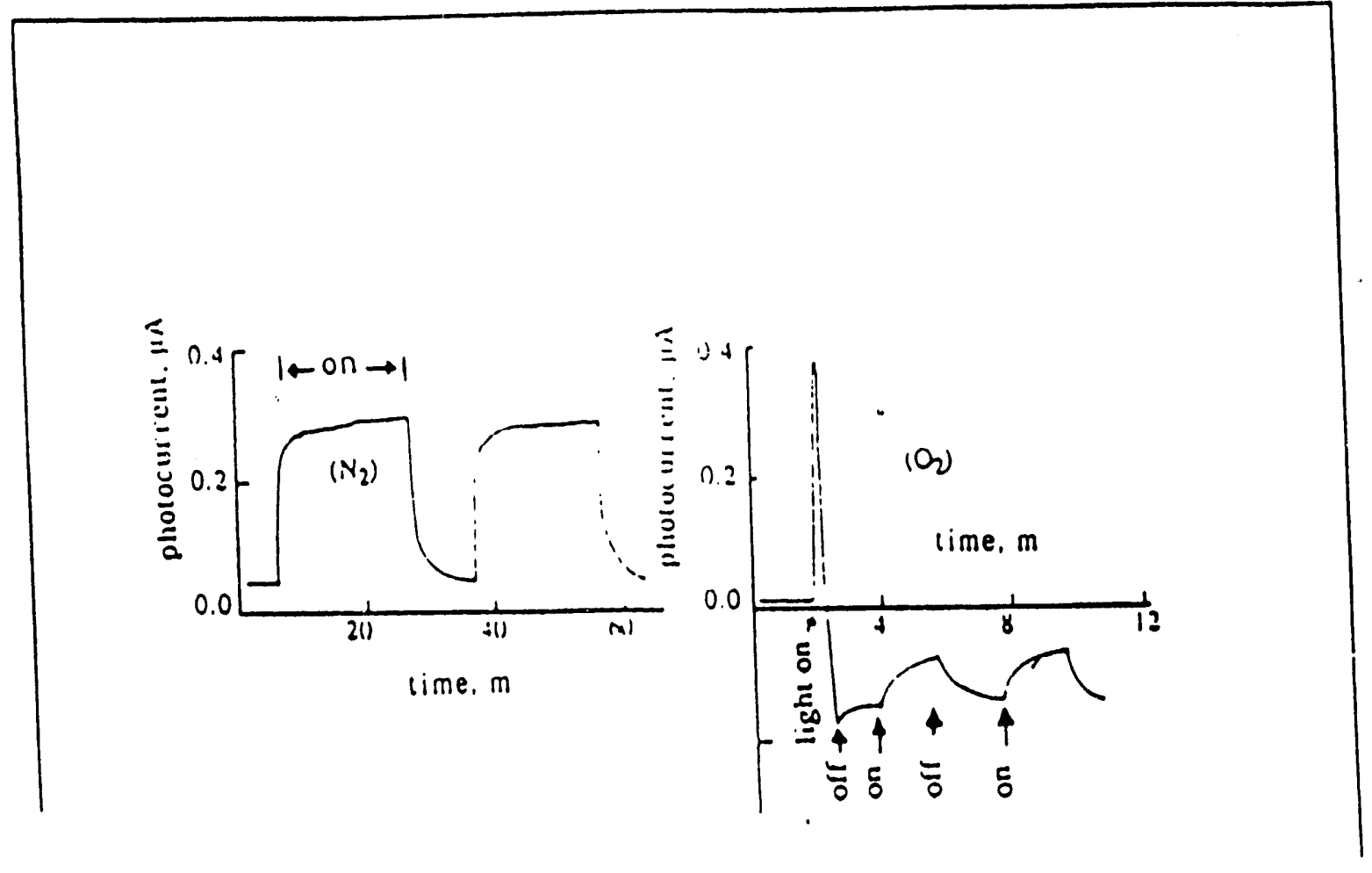

Fig. 5: Dependence of the electron collection current from slurried Pd-activated (3 weight \% Pd) $\mathrm{TiO}_{2}$ particles by a vitreous carbon electrode maintained at $350 \mathrm{mV}$ vs $\mathrm{Ag} / \mathrm{AgCl}$. $0.3 \mathrm{M} \mathrm{NaCl}, 1.6 \mathrm{M}$ methanol in water. The palladium co-catalyst causes complete discharge of the electrons to $\mathrm{O}_{2} ;$ as a result only positive charge on the particles is observed. 


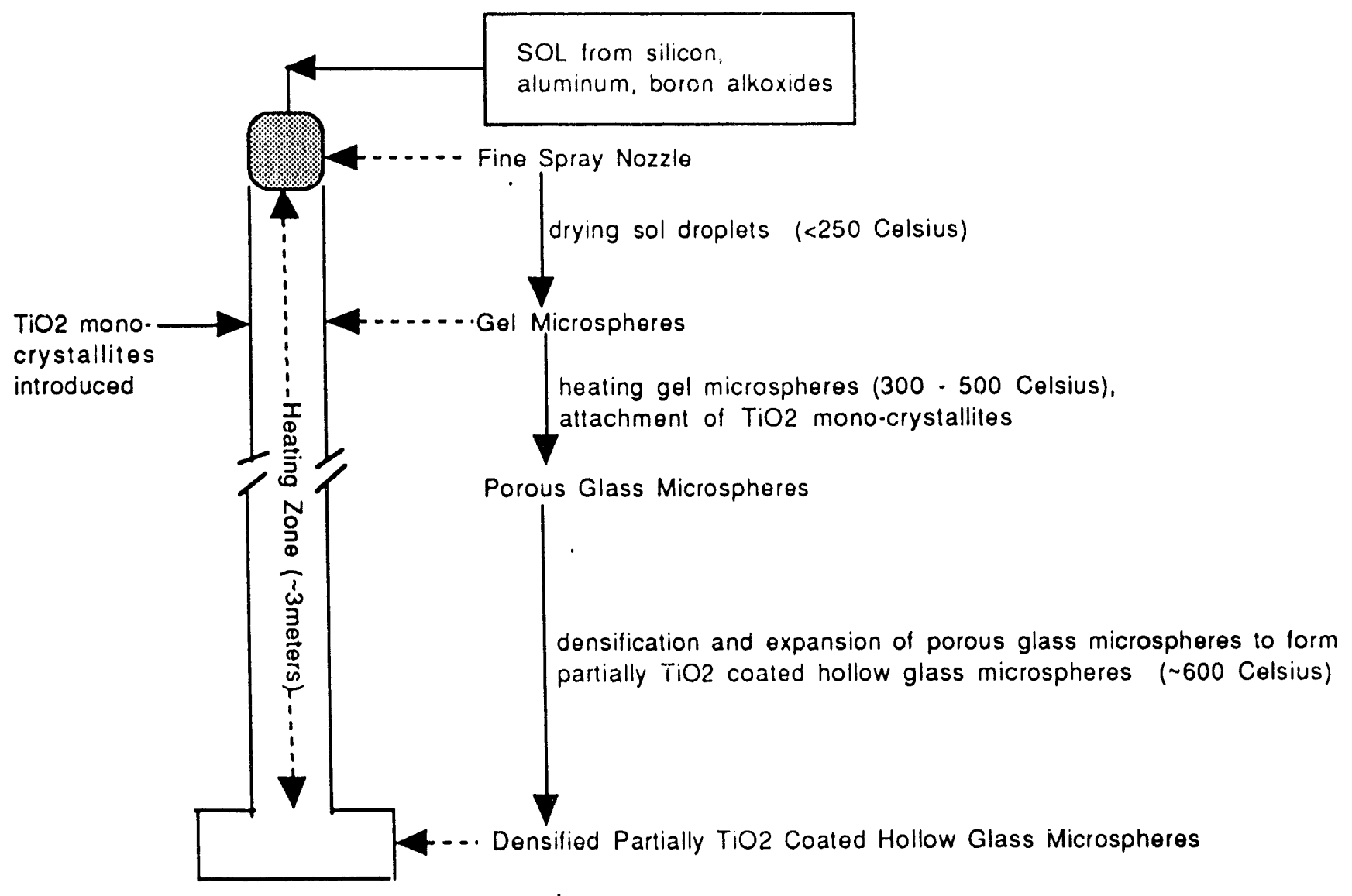

Figure 6. Schematic diagram of new process for production of engineered hollow TiO2 coated glass microspheres 

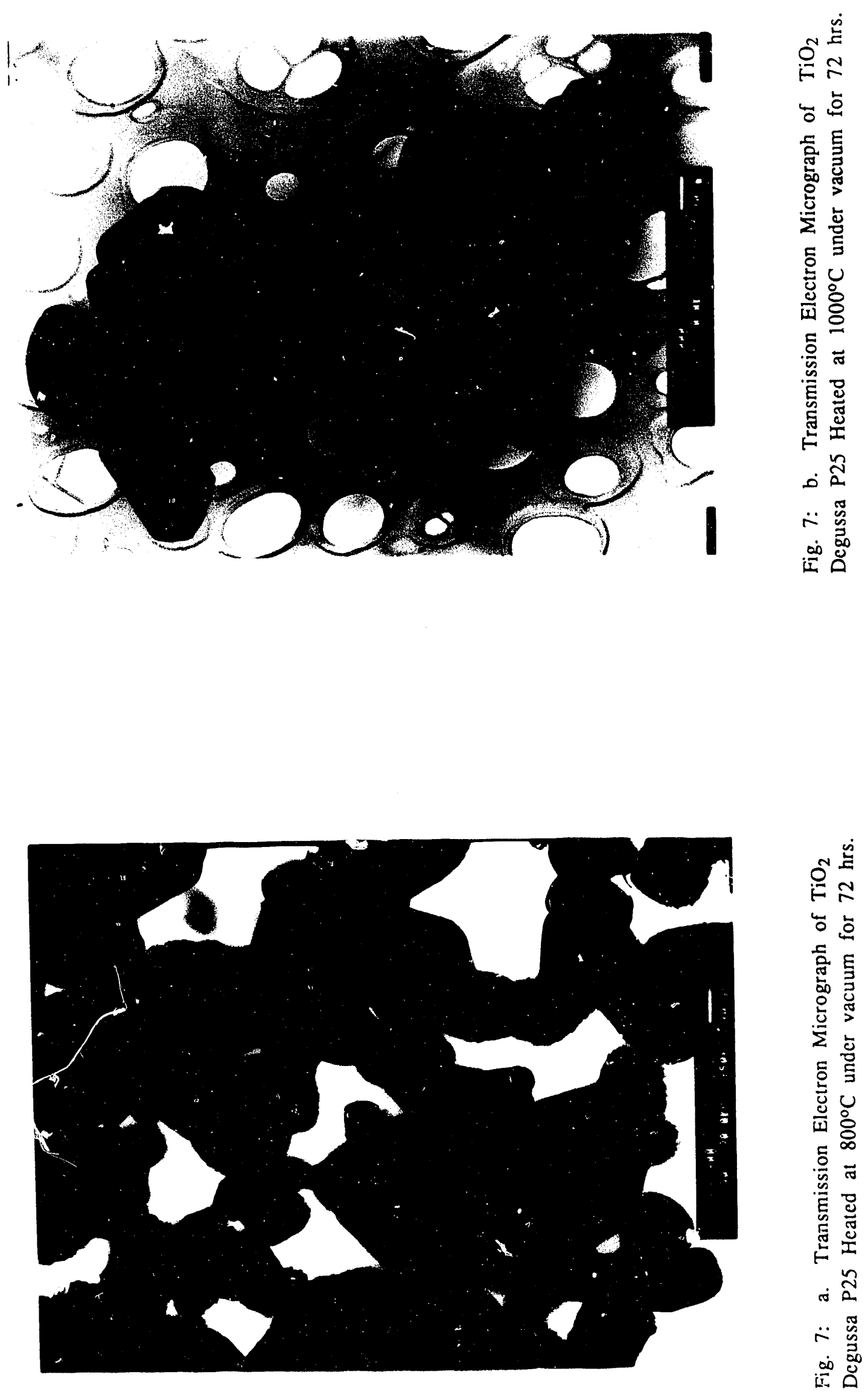

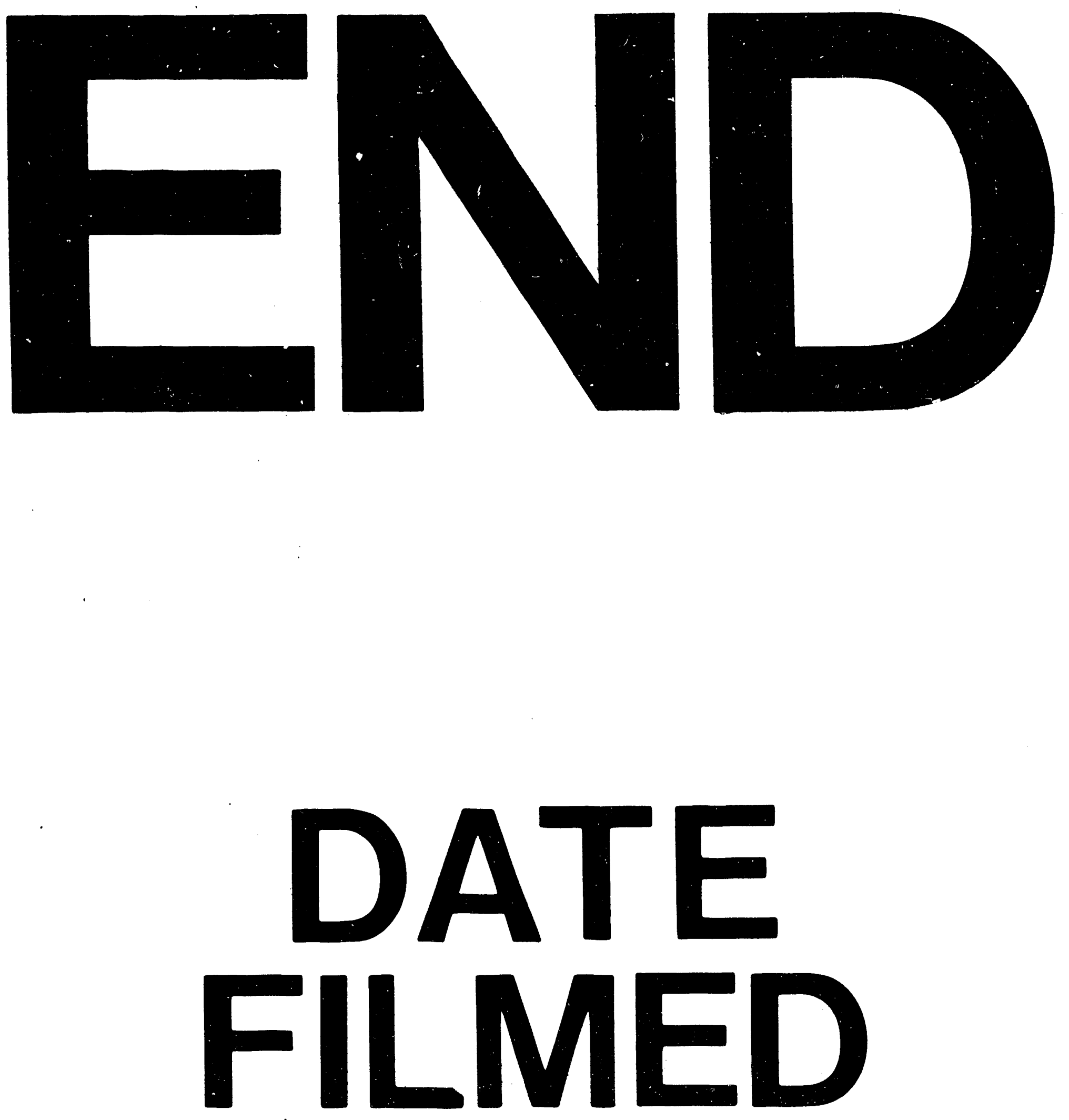

I

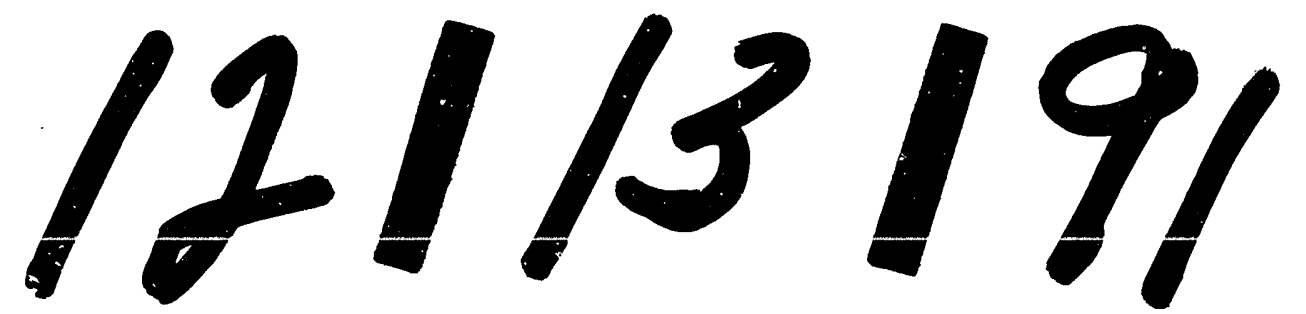


